\title{
Stabilization of high-solid compositions based on nitrate ester plasticizers
}

\author{
(C) Yulia V. Pilyugina, ${ }^{+}$Sergey A. Zyablitsky, Larisa G. Egorova, and Valery N. Mashkovtsev \\ JSC "Federal Research and Production Center "Altay". Socialisticheskayast St., 1. Biysk, 659322, Altay. \\ Russia.Phone: +7 (3854)30-14-78. E-mail: 13.09.1994@mail.ru
}

*Supervising author; ${ }^{+}$Corresponding author

Keywords: chemical stabilizers, high-energy system,gas evolution, diphenylamine, resorcinol, methylnitroaniline, nitrate ester plasticizers, aluminum spherical powder.

\section{Abstract}

This article analyzes the interaction of various stabilization systems based on nitrate ester plasticizers. This subject is relevant since improvement of operational characteristics, the decomposition slowing and increase of the chemical resistance are fundamental for high-energy systems.

Model high-energy systems MS-1 and MS-2 were investigated. MS-1 is based on the active fuel-binder FB-1 using butyl nitrile rubber. MS-2 is based on the active FB-2 using polyurethane rubber, aluminum spherical powder, ammonium perchlorate, nitramine, process and stabilizing additives. Diphenylamine, resorcinol, methyl nitroaniline and mixtures thereof were used as a chemical resistance stabilizer.

In the article the studies of stabilizing systems such as diphenylamine and resorcinol, diphenylamine and methylnitroaniline, diphenylamine are given. To establish the effect of the system stabilization the level of gas evolution was determined on the basis of various nitroether plasticizers.

As a matter of record the gas evolution level was found to have decreased by $40 \%$ in the model highenergy systems MS-1 based on active FB-1 using butyl nitrile rubber and methyl nitroaniline and diphenylamine stabilization system and by $6 \%$ in MS-2 that is based on active FB-2 using polyurethane rubber and methylnitroaniline and diphenylamine, nitrogen oxides being also absent in both systems.

\section{References}

[1] S.A. Zyablitsky, A.V. Kornienkova, N.F. Panchenko, E.V. Romanova. Ways to increase the thermal stability of "active" fuel-binders. Proceedings of the VII All-Russian Scientific and Technical Conference of Young Scientists "Prospects for the Creation and Use of Condensed High-Energy Materials". Biysk. 2018. P.48-50. (russian)

[2] A.V. Kostochko, V.M. Kazban. Gunpowders, rocket solid propellants and their properties. Physicochemical properties of gunpowder and rocket solid propellants: training manual. Feder. Agency for Education, Kazan State Technological University. Kazan: KSTU. 2011. P.368. (russian)

[3] B.S. Svetlov. Thermal decomposition of nitrate esters: Doctorate Thesis. Moscow: Moscow Institute of Chemical Engineering named after D.I. Mendeleev. 1970. 360p. (russian)

[4] E.A. Petrov, T.V. Sokolova, S.V. Ershova. Investigation of physical stability of industrial explosives containingnitrate esters. Bulletin of the Scientific Center for Work Safety in the Coal Industry of the Scientific Center of Oriental Research Institute. Kemerovo. 2006. No.1. P.38-44. (russian) 